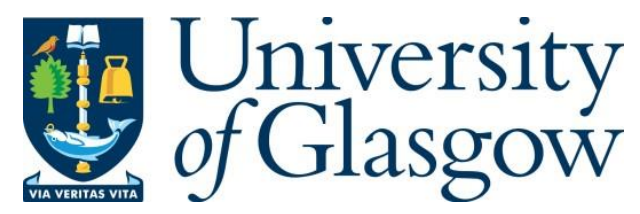

Wang, Y., Zuo, S., Ghannam, R. and Heidari, H. (2019) Smart Multi-Sensory Ball for Water Quality Monitoring. In: IEEE Asia Pacific Conference on Postgraduate Research in Microelectronics and Electronics (PrimeAsia 2018), Chengdu, China, 26-30 Oct 2018, pp. 51-54. ISBN 9781538695913.

There may be differences between this version and the published version. You are advised to consult the publisher's version if you wish to cite from it.

$\underline{\text { http://eprints.gla.ac.uk/168940/ }}$

Deposited on: 14 September 2018

Enlighten - Research publications by members of the University of Glasgow http://eprints.gla.ac.uk 


\title{
Smart Multi-Sensory Ball for Water Quality Monitoring
}

\author{
Yusu Wang, Siming Zuo, Rami Ghannam and Hadi Heidari \\ Microelectronics Lab (meLAB), School of Engineering, University of Glasgow, G12 8QQ, UK \\ hadi.heidari@glasgow.ac.uk
}

\begin{abstract}
Electronic sensors and wireless communications have enabled a long-distance and realtime monitoring of water quality. In this paper, we present a smart multi-sensory device, remotely measuring and monitoring physical parameters of the water in real time. The proposed device is a $10 \mathrm{~cm}$-diameter enclosure, consisting of an embedded battery, a voltage regulator, an Inertial Measurement Unit (IMU), and a communication chip with the 3D-printing cases. This smart multi-sensory enclosure or smart "ball" can successfully communicate with a personal computer in the real-time via wireless communication. Finally, the collected data can be directly displayed and post-processed to show real-time changes in the parameters.
\end{abstract}

Keywords - Smart Multi-Sensory Ball; 3D Printing; Water Quality Monitoring; Remotely Monitoring.

\section{INTRODUCTION}

A complete assessment of water quality consists of three components: 1) hydrodynamic features, related with a hydrological cycle system of the water body; 2) physical \& chemical properties, determined by the climatic, geomorphological and geochemical conditions; and 3) biological characteristics, governed by a variety of environmental conditions as well as the physiological performance of individual organisms [1].

Compared to traditional lab-based water quality monitoring, the real-time water monitoring with specific sensors is easier, more high-efficiency and less fresh supplies required [2]. Real-time remote monitoring of water quality: a review of current applications and advancements in sensor, telemetry, and computing technologies, the real-time remote monitoring (RTRM) and sensing technologies have a great future to evaluate water quality [3].

For modern water quality monitoring, mathematical modelling is a powerful tool to assess water quality of complex real world with the computer. The model reflects physical, chemical and biological processes, as well as the interaction of the influencing factors. Take an example of the Water Quality Analysis Simulation Program Version 4 (WASP4), it can be used to analyse many water quality problems in different types of water body [4].

In this project, three main parameters are obtained to evaluate water quality: acceleration, angular velocity, and magnetic field strength. There are total 3 stages of the project process as Fig. 1.

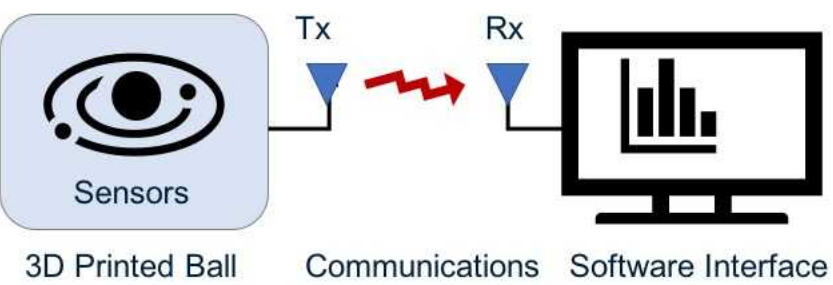

Figure 1. The envisioned of the project process.

Acceleration and angular velocity can be used to apply in hydrodynamics to build up the physical model of water quality. Take an example of acceleration, the material derivative can be calculated by acceleration as

$$
\mathrm{f}=\frac{\mathrm{Dq}}{\mathrm{Dt}}=\frac{\partial \mathrm{q}}{\partial \mathrm{t}}+(\mathrm{q} \cdot \nabla) \mathrm{q}
$$

where $\frac{D q}{D t}$ represents the substantial derivative of $\mathrm{q}$ or the derivative following the motion, and $\frac{\partial q}{\partial t}$ represents time differentiation of $q$ at a fixed point in space [5].

Magnetic field strength is an important parameter to detect nitrates and contamination of water [2]. In the principle of electromagnetic current meter as Fig. 2, the magnetic field strength is used to calculate velocity in pipes as Eq. 1 [6]

$$
\mathrm{u}=\frac{E_{m}}{F_{S} d C_{e}}
$$

where $E_{m}$ is the electromagnetic force generated (Volts), $F_{S}$ the magnetic field strength (Tesla), $d$ the pie diameter, and $C_{e}$, a dimensionless discharge coefficient.

\section{SMART MULTI-SENSORY BALL}

The main purpose of this project efforts is to design and implement the first multi-sensor equipment to simultaneously measure and remotely monitor acceleration, angular velocity, magnetic field strength and other physical parameters in an application, such as the direction of water flowing. Because the technology of modern water quality monitoring is encouraged in processing data by computer rather than human, the smart multi-sensor ball could transmit data to the computer and visualizes directly, eliminating steps of transferring data. It will have great development potential in the water quality monitoring area.

There are 3 stages for data processing. The first stage is that every parameter is received by IMU (JY901) as 8-bit data. 

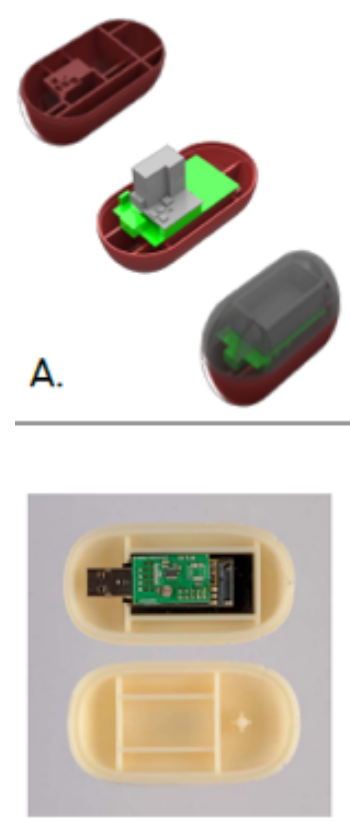

C.
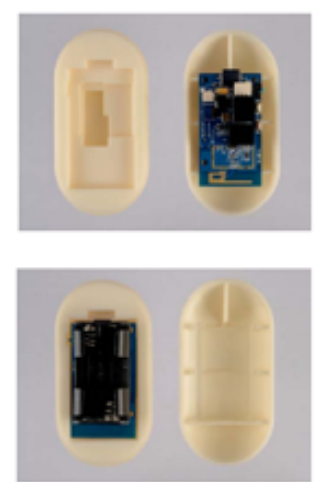

B.

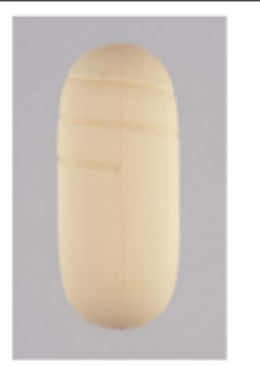

D.

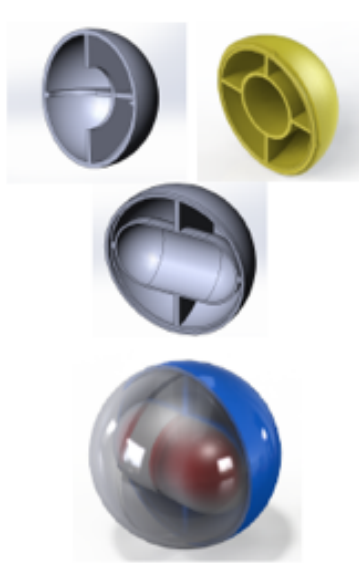

A.

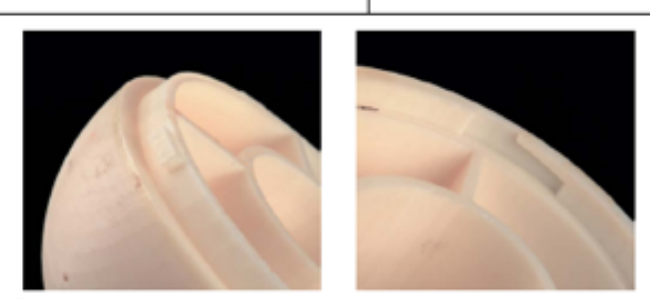

Figure 2. Designs for the inner and outer case.

Take an example of acceleration, the data bit with the specification of each bit as Table I.

The second stage is communication. The data is directly transferred to HC-12 because both JY901 and HC-12 support Transistor-transistor logic (TTL), a logic family built from bipolar junction transistors (BJT). Afterward, the data is transferred between two HC-12 through wireless communication. Then the data is converted from TTL to USB to be read by Computer through TTL-USB Converter.

The data bit is extracted and calculated. Then every parameter is shown on the software interface with charts in the real time. Also, take an example of Acceleration, the calculation formulas are as follows:

$$
\begin{aligned}
& a_{x}=\frac{((A x H \ll 8) \mid A x L)}{32768} * 16 g \\
& a_{y}=\frac{((A y H \ll 8) \mid A y L)}{32768} * 16 g
\end{aligned}
$$

TABLE I. THE MEANING OF EACH DATA

\begin{tabular}{cc}
\hline Data & Meaning \\
\hline AxL & The lower part of Accelerations in the x-axis \\
\hline AxH & The higher part of Accelerations in the x-axis \\
\hline AyL & The lower part of Accelerations in the y-axis \\
\hline AyH & The higher part of Accelerations in the y-axis \\
\hline AzL & The lower part of Accelerations in the z-axis \\
\hline AzH & The higher part of Accelerations in the z-axis \\
\hline TL & The lower part of Temperature \\
\hline TH & The higher part of Temperature \\
\hline SUM & Checksum \\
\hline
\end{tabular}

$$
\begin{gathered}
a_{z}=\frac{((A z H \ll 8) \mid A z L)}{32768} * 16 g \\
\mathrm{~T}=((\mathrm{TH} \ll 8) \mid \mathrm{TL}) / 100^{\circ} \mathrm{C} \\
\text { Sum }=0 \times 55+0 \times 51+\mathrm{AxH}+\mathrm{AxL}+\mathrm{AyH} \\
+\mathrm{AyL}+\mathrm{AzH}+\mathrm{AzL}+\mathrm{TH}+\mathrm{TL}
\end{gathered}
$$

The last stage is showing real-time data and plots in the software interface. The interface used in this paper is the commercial version. It is stable with fast calculation speed.

\section{DESIGN AND FABRICATION}

First of all, in the process of water quality assessment, the designed equipment is placed on the water surface or underwater to measure physical parameters of water body being tested. In order to keep every part works normally over a period, every electronic component should be kept in a dry and stable space, the case needs to be designed to perfectly match with every component with good waterproofness and durability.

$3 \mathrm{D}$ printing refers to the fabrication of a physical, 3D part of arbitrary shape directly from numerical description (typically a CAD model) by a quick, totally automated, and highly flexible process without any tooling [7]. The basic 3DP process consists of following steps [8]:

1. Create a CAD model of the design.

2. Convert the CAD model to STL file format.

3. Slice the STL file into $2 D$ cross-sectional layers.

4. Grow the prototype. 


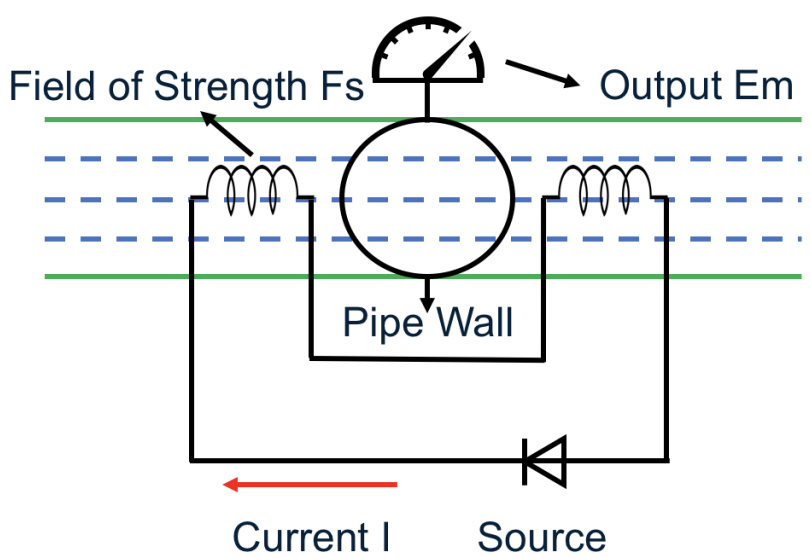

Figure 3. The basic structure of the electromagnetic current meter.

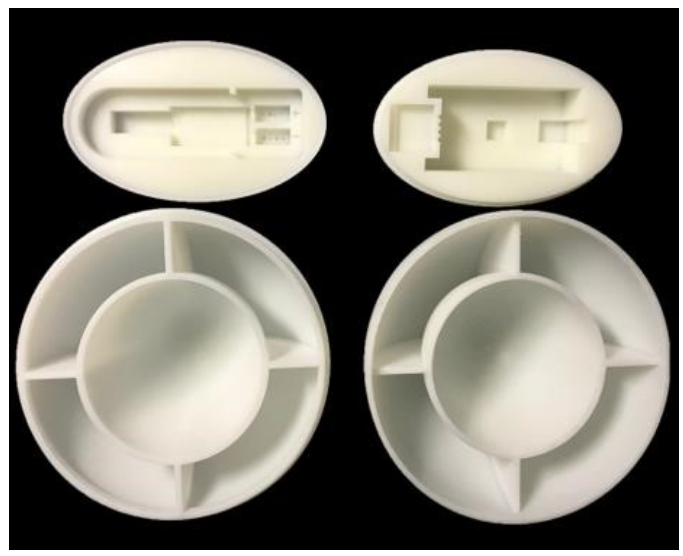

Figure 4. Inner case A (top right), Inner case B (top left), Outer case A (bottom right) and Outer case B (bottom left).

\section{Clean and finish the model.}

The success method for rapid prototyping of sensor component enclosures makes it possible to design 3Dprinting cases to preserve electronic components, especially the sensor from damage in continuous normal operation conditions [9-14].

To gain the final ideal 3D-printing model, it is estimated to print 2-3 times. According to the above conditions, customizable Stereo Lithography Apparatus (SLA) 3Dprinting model is a good choice with lots of advantages such as accessible, cheap, high-precision and so on.

In order to keep electronic component away from water and stress, the design of 3D-printing model will take a new method to the exact fit of a void and avoid any electronic components relative sliding compared the inner case or outer case as Fig. 3 [6].

The 3D-printing case includes four parts: two inner cases (Inner Case A\&B) and two outer cases (Outer Case A\&B) as in Fig. 4. Inner case A is placed Microcontroller (mbed NXP LPC1768) and sensor (JY901). Inner case B leaves a space for battery box (includes 2 button cells) and communication chip (HC-12). The Outer case A\&B are used to support and protect inner cases from damage and water.

\section{EXPERIMENTAL RESULTS}

\section{A. Acceleration}

The experimental results of the pulling water with a hand to the $\mathrm{X}, \mathrm{Y}$ and $\mathrm{Z}$ directions is illustrated in the Fig. 5(a) $5(\mathrm{c})$, respectively.

\section{B. Angle Velocity}

Rotate the ball on the $\mathrm{x}-\mathrm{y}$ axis plane as Fig. 6. Angle Velocity changed when pulled water in the z-axis.
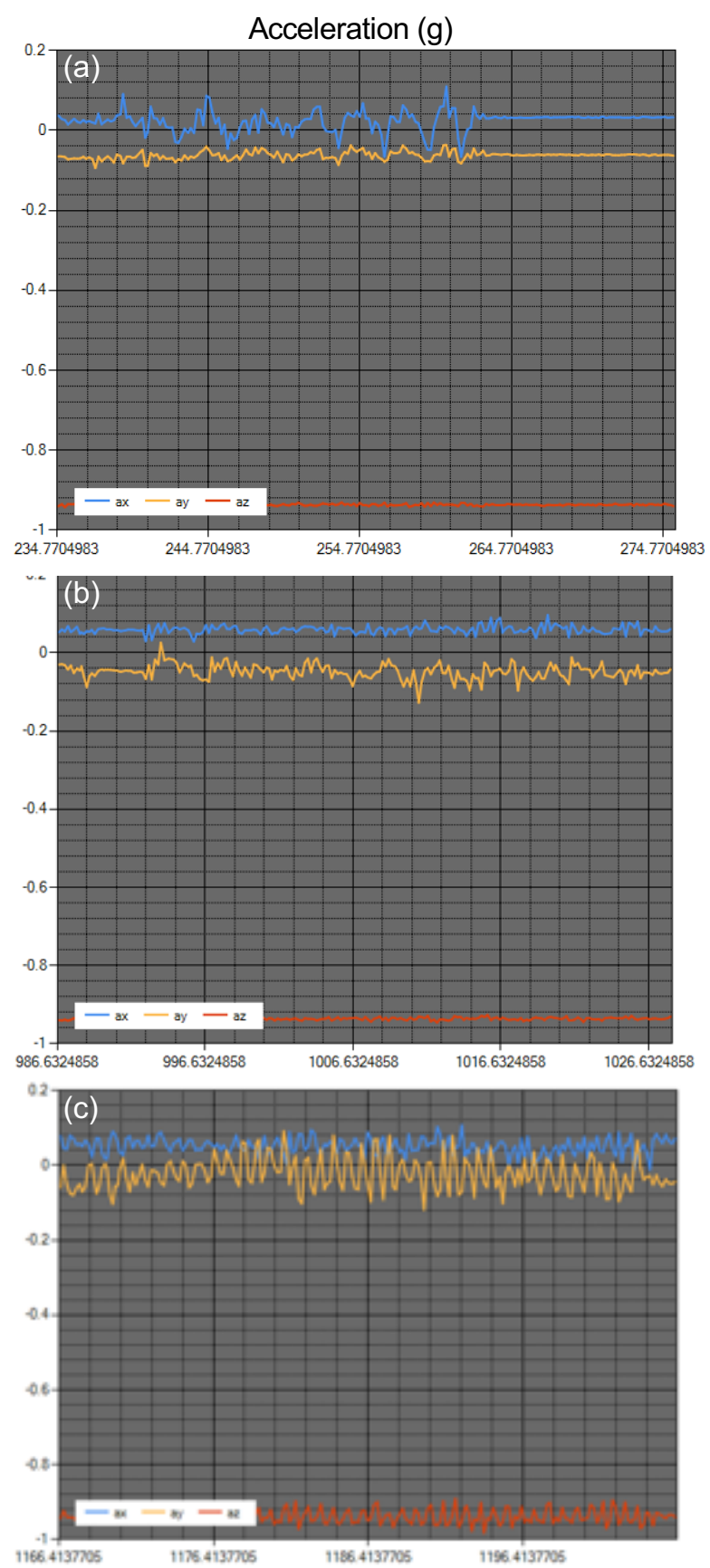

Figure 5. Acceleration changed when pulled water in the (a) X-axis, (b) Yaxis and (c) Z-axis. 


\section{Magnetic Field Strength}

A magnet is placed in the $\mathrm{X}$ direction, the $\mathrm{Y}$ direction, and the $\mathrm{Z}$ direction in proper order as Fig. 7.

\section{CONCLUSION}

In this paper, the smart multi-sensor ball successful measure the acceleration, angle velocity, magnetic field strength and angle on the water surface in real time. And every parameter in three-dimensional space (x-axis, y-axis, and z-axis) was printed on the interface with plots.

But it still needs some future works: First, the split joint between cases can be designed more closely in another way, e.g. screw thread. Because of the redundant space of mbed, the remaining elements can be arranged less closely. For example, put sensor and communication chip in the same inner case while putting the battery in another inner case.

Second, the connection of the jumper is not very strong to make data transmission unstable. It could be better to buy a crimping plier to firmly fix line and terminal. In the case of excess space, try not to connect directly to the circuit, but to add the jumper for easy testing.

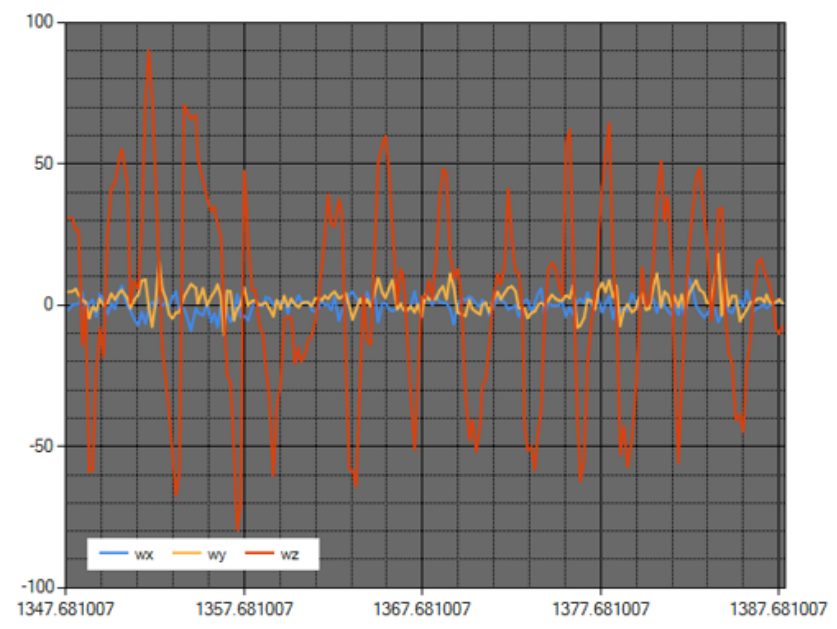

Figure 6. Angle Velocity changed when pulled water in the z-axis

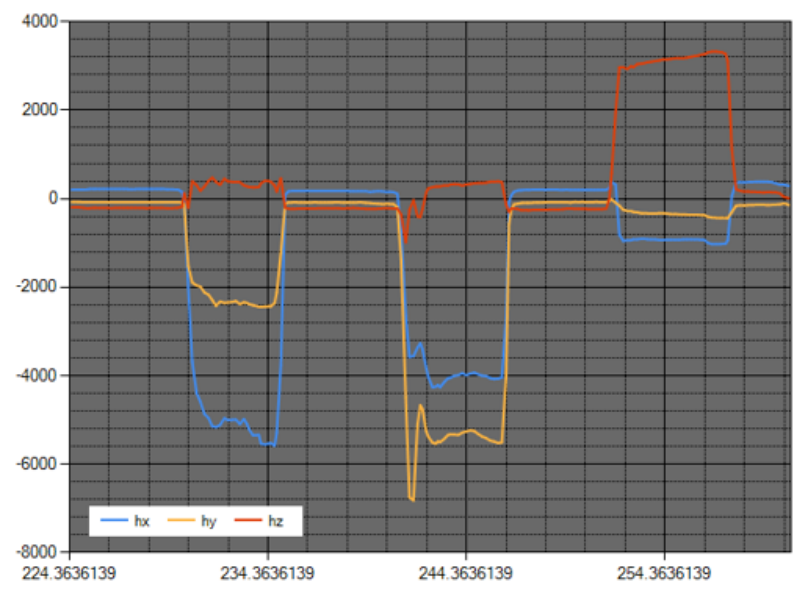

Figure 7. Magnetic field strength changed when put a magnet in the $\mathrm{x}$-axis, $\mathrm{y}$-axis, and z-axis.
Third, the measurement of physical parameters is not enough for a water quality monitoring start multi-sensor ball. So maybe more sensors with other functions such as detecting chemical materials should be work together to get more useful information to do water quality assessment.

\section{REFERENCES}

[1] Chapman, Deborah V., and World Health Organization, Water quality assessments: a guide to the use of biota, sediments, and water in environmental monitoring, $2^{\text {nd }}$ Edition, E\&FN SPON, an imprint of Chapman \& Hall (1996).

[2] Mukhopadhyay, Subhas Chandra, and Alex Mason, Smart sensors for real-time water quality monitoring, $1^{\text {st }}$ Edition, Springer (2013), Monitoring Pollutants in Wastewater: Traditional Lab Based versus Modern Real-Time Approaches.

[3] Howard B., Real-time remote monitoring of water quality: a review of current applications, and advancements in sensor, telemetry, and computing technologies, Journal of Experimental Marine Biology and Ecology, 300.1-2 (2004): 409-448.

[4] Ambrose, Robert B. WASP4, a hydrodynamic and water quality model: model theory, user's manual and programmer's guide, $1^{\text {st }}$ Edition, US Environmental Protection Agency (1988).

[5] Horace Lamb, Hydrodynamics, $4^{\text {th }}$ Edition, Cambridge University Press (1916).

[6] Martin, James L., and Steven C. McCutcheon, Hydrodynamics and transport for water quality modeling, $1^{\text {st }}$ Edition, CRC Press, 1998.

[7] Noorani, Rafiq, 3D Printing: Technology, Applications, and Selection, $1^{\text {st }}$ Edition, CRC Press, 2017.

[8] Kai, Chua Chee, Leong Kah Fai, and Lim Chu-Sing, Rapid prototyping: principles and applications in manufacturing, World Scientific Publishing Co., Inc. (2003).

[9] Summerville, Douglas H, Embedded Systems Interfacing for Engineers using the Freescale HCS08 Microcontroller II: Digital and Analog Hardware Interfacing, $2^{\text {nd }}$ Edition, Synthesis Lectures on Digital Circuits and Systems 4.1 (2009): 1-139

[10] V. Nabaei, et al., "Magnetic Biosensors: Modelling and Simulation," Biosensors Bioelectronics, vol. 103, pp. 69-86, 2018.

[11] K. O. Htet, et al., "Switched Capacitor DC-DC Converter for Miniaturised Wearable Systems," in 2018 IEEE International Symposium on Circuits and Systems (ISCAS), 2018, pp. 1-5.

[12] K.-M. Lei, et al., "A Handheld High-Sensitivity Micro-NMR CMOS Platform With B-Field Stabilization for Multi-Type Biological/Chemical Assays," IEEE J. Solid-State Circuits, vol. 52, pp. 284-297, 2017.

[13] S. Samyak, et al., "On-chip Magnetoresistive Sensors for Detection and Localization of Paramagnetic Particles," in Proc. of IEEE SENSORS Conference, Glasgow, UK, 2017.

[14] X. Liang, et al., "Wearable Capacitive-Based Wrist-Worn Gesture Sensing System," in IEEE New Generation Circuits Systems (NGCAS), 2017, pp. 181-184. 